\title{
A FORMAÇÃO E O TRABALHO DOCENTE, AS TECNOLOGIAS MÓVEIS E A UNESCO
}

\author{
TRAINING AND TEACHING WORK, \\ MOBILE TECHNOLOGIES AND UNESCO
}

\section{LA FORMACIÓN Y EL TRABAJO DOCENTE, TECNOLOGÍAS MÓVILES Y LA UNESCO}

\section{RESUMO}

Cláudio Lúcio Mendes ${ }^{1}$, Rui Maurício Fonseca Evangelista ${ }^{2}$

Neste artigo, investiga-se como a formação e o trabalho docente são tratados nas recentes proposições da UNESCO sobre tecnologias e aprendizagens móveis. Discorre-se sobre alguns documentos publicados durante a pandemia de Covid-19, porém o foco das análises dá-se em documentos elaborados em 2012 e 2014 . A investigação apoia-se teoricamente na noção de governamentalidade de Michel Foucault e nas discussões de Stephen Ball relacionadas a essa mesma noção no contexto do neoliberalismo contemporâneo. Analiticamente, descreve-se como a UNESCO propõe as tecnologias e as aprendizagens móveis como importantes ferramentas para transformar a educação, defendendo sua utilização na formação e no trabalho docentes, especialmente em países pobres e em desenvolvimento. A seguir, problematiza-se quem financia os documentos analisados, quais são os possíveis interesses dos financiadores e as questões de mercado as quais tal financiamento pode estar relacionado. Conclui-se apontando as proposições descritas como parte de mecanismos de controle da conduta a favor e fazendo parte de mentalidades contemporâneas pautadas no neoliberalismo de mercado.

PALAVRAS-CHAVE: UNESCO. Formação de professores. Trabalho docente. Tecnologia móvel. Aprendizagem móvel.

\begin{abstract}
In this article, it investigates how training and teaching work are treated in UNESCO's proposals on mobile technology and learning. Some documents published during the Covid-19 pandemic are discussed, but the focus of the analysis is on documents prepared in 2012 and 2014. The research draws theoretically on Michel Foucault's perspective of governmentality and Stephen Ball's discussions related to this notion in the context of contemporary neoliberalism. Analytically, it describes how UNESCO proposes mobile technology and mobile learning as important tools to transform education, advocating their use in teacher training and work, especially in poor and developing countries. Next, we discuss who finances the documents analyzed, what are the possible interests of the financiers and the market issues to which such financing may be related. It concludes by pointing out the proposals described as part of conduct control mechanisms in favor and being part of contemporary mentalities based on market neoliberalism.
\end{abstract}

KEYWORDS: UNESCO. Teacher training. Teaching work. Mobile technology. Mobile learning.

\footnotetext{
${ }^{1}$ Doutor em Educação - Universidade Federal do Rio Grande do Sul (UFRGS). Porto Alegre, RS - Brasil. Professor do Departamento de Educação - Universidade Federal de Lavras (UFLA). Lavras, MG - Brasil. E-mail: claudio.mendes@ufla.br

${ }^{2}$ Mestre em Educação - Universidade Federal de Ouro Preto (UFOP). Ouro Preto, MG - Brasil. Professor da Educação Básica. Ouro Preto, MG - Brasil. E-mail: ruimauriciogeo@gmail.com

Submetido em: 04/06/2021 - Aceito em: 17/08/2021
}

(C) ETD-Educação Temática Digital Campinas, SP $\quad$ v.24 $\quad$ n.1 $\quad$ p. 151-170 jan./abr. 2022




\section{RESUMEN}

En este artículo, se investiga cómo se abordan la formación y el trabajo docente en las propuestas de la UNESCO sobre tecnología móvil y aprendizaje móvil. Se discuten algunos documentos publicados durante la pandemia de Covid-19, pero el análisis se centra en los documentos preparados en 2012 y 2014 . La investigación se basa teóricamente en la noción de gubernamentalidad de Michel Foucault y en las discusiones de Stephen Ball relacionadas con esta noción en el contexto del neoliberalismo contemporáneo. Analíticamente, describe cómo la UNESCO propone la tecnología móvil y el aprendizaje móvil como herramientas importantes para transformar la educación, abogando por su uso en la formación y el trabajo de los profesores, especialmente en los países pobres y en desarrollo. A continuación, se analiza quién financia los documentos analizados, cuáles son los posibles intereses de los financiadores y las cuestiones de mercado con las que puede estar relacionada dicha financiación. Concluye señalando las propuestas descritas como parte de los mecanismos de control de conducta a favor y como parte de las mentalidades contemporáneas basadas en el neoliberalismo de mercado.

PALAVRAS-CLAVE: UNESCO. Formación de profesores. Trabajo docente. Tecnología móvil. Aprendizaje móvil.

\section{INTRODUÇÃO}

Em 11 de março de 2020 a Organização Mundial da Saúde (OMS) declara estado de pandemia. Diversas práticas foram abruptamente interrompidas e/ou modificadas, dentre elas, aquelas relacionadas à educação escolar. Observou-se uma multiplicidade de tempos, estratégias e processos de subjetivação para orientar as instituições e os professores a migrarem para o denominado Ensino Remoto Emergencial (CASTIONI et al, 2021). No mês seguinte, em um documento conjunto de 4 organismos internacionais recomendou-se que "as decisões sobre a reabertura exigirão que os países reúnam rapidamente informações estratégicas sobre como escolas, professores, estudantes e comunidades estão lidando com o fechamento [das escolas] e com a pandemia" (UNESCO; UNICEF; BM; PMA, 2020). Ao mesmo tempo, no âmbito de uma série de documentos on-line (Planejando a educação, construindo o futuro), a Organização das Nações Unidas para a Educação, a Ciência e a Cultura (UNESCO) apresentou cinco documentos curtos denominados 'Cinco passos para apoiar a educação para todas as pessoas no contexto da COVID-19' discutindo a importância de: 1) coordenar, planejar e comunicar o que será feito pelos gestores - tanto nos âmbitos governamentais, em suas diferentes esferas de poder, como no âmbito escolar -, aos docentes e às famílias; 2 ) manter a capacidade de ensinar (pelas escolas e pelos professores) e de aprender pelos alunos, empregando de tecnologias digitais relacionadas à EAD, às aprendizagens móveis, on-line e remotas, garantindo os salários dos professores, mesmo em trabalho remoto; 3) ofertar apoio e orientação sobre temas ligados à pandemia (saúde mental, prevenção de doenças, atividade física) para alunos, docentes, gestores e famílias, bem como formação para trabalhar com as tecnologias digitais; 4) oferecer formação sobre higiene e saúde, tratando, também, de problemas relacionados a abuso, violência e bullying domésticos em decorrência do confinamento; 5) elaborar planos para reabertura das escolas focados no financeiro, na infraestrutura e nos recursos humanos, dando atenção à

(C) ETD- Educação Temática Digital

Campinas, SP v.24

n.1

p. $151-170$

jan./abr. 2022 
participação da comunidade escolar no planejamento (UNESCO, 2020). Concomitante a essa série, lançou-se uma outra (UNESCO e COVID-19: Notas informativas de educação), constituída por pequenos textos e configurada em um modo bem mais sintético, didaticamente organizada para leituras rápidas e objetivas, tratando dos mesmos temas e assuntos da série 'Planejando a educação, construindo o futuro'. No documento 'Informe de seguimiento de la educación en el mundo 2020' (UNESCO, 2020a) deu-se foco às tecnologias digitais para inclusão de alunos (crianças, adolescentes e adultos) marginalizados e/ou em situação de risco, centralmente por meio de tecnologias assistivas para portadores de deficiência em vários países ${ }^{3}$. Várias experiências, tentativas e políticas públicas relacionadas à oferta de ensino em tempos de pandemia foram descritas. Em alguns casos, experiências e a necessidade de formação de professores a favor do emprego de tecnologias móveis nos processos formais escolares de aprendizagem foram apresentadas. No entanto, não foram propostos modelos ou procedimentos de ensino e aprendizagem, como foi feito na série de documentos elaborada sobre tecnologias móveis e educação (2012-2014).

Diante da pandemia, a UNESCO criou a 'Coalizão Global de Educação'. Tal coalização estaria presente em 112 países, beneficiando mais de 400 milhões de alunos e 12 milhões de professores, direta ou indiretamente. A sua plataforma on-line está focada em três eixos: conectividade, professores e gênero. Em um dos documentos lançados em março de 2021, a importância da universalização da internet de qualidade, a capacitação dos profissionais e demais envolvidos na educação e a produção de pesquisas visando a compreensão da pandemia e de seus efeitos na educação - especialmente no que se refere à gênero, aos grupos marginalizados e às comunidades desassistidas social e economicamente - foram destacadas (UNESCO, 2021). Dois aspectos chamaram a atenção nos documentos a discutirem a educação no contexto da pandemia: 1) a importância dada à conduta da conduta dos professores e ao seu trabalho, mesmo que remoto; 2) a presença do tema 'tecnologia digital e educação' em vários documentos da UNESCO, ora tratando de aprendizagem móvel, ora de tecnologia em geral. Como veremos, tanto o foco nas tecnologias móveis quanto o foco na conduta da conduta não são aspectos novos nos Estados contemporâneos e nos documentos da UNESCO.

Sobre a conduta da conduta, desde a década de 1990 está em curso uma série de mecanismos de controle sobre a formação e o trabalho docentes, sendo sua mentalidade

\footnotetext{
${ }^{3}$ Essa é a versão em espanhol do 'Relatório de Monitoramento Global da Educação' (2020), de 478 páginas - há uma versão em português, muito sintética, de 36 páginas. A UNESCO tem produzido esses relatórios a partir de 2002, sendo o 170 relatório desde então, todos eles pautados na noção de Educação para Todos. Essa noção pode ser sintetizada como a promoção de "aprendizado formador de habilidades, valores e atitudes capazes de melhorar a vida individual e coletiva", exigindo "mudanças nos contextos sociais, econômicos, políticos e culturais" dos países (REZENDE, 2019, p. 128), apoiando-se na Declaração Mundial pela Educação para Todos (1990).
}

(C) ETD-Educação Temática Digital

Campinas, SP

v.24

n.1

p. $151-170$

jan./abr. 2022 
fundadora e orientadora baseada em leituras sobre o neoliberalismo (BALL, 2001; 2014). Esses mecanismos vêm sendo encontrados em várias reformas educacionais, dando atenção àquelas orientadas para a formação inicial e continuada, sob a premissa de transformar o cotidiano do professor (em consequência, o cotidiano do aluno, do ensino e da aprendizagem) nas escolas públicas e privadas (EVANGELISTA, 2017). Sob inspiração foucaultiana - levando em conta as releituras e as noções produzidas por Stephen Ball -, afirmamos que tais mecanismos de controle (entendidos neste texto como procedimentos de governo de Estado, dos outros e de si, uma governamentalidade pautada na conduta da conduta) baseiam-se em práticas de mercado, tendo uma ligação direta com os mesmos interesses que justificam essas práticas.

Igualmente envolvida com interesses de mercado, a expansão das tecnologias móveis ocorre em grande velocidade, envolvendo a ampliação do número de antenas de emissão de sinais, lançamento de satélites, além da disseminação de vários tipos de aparelhos usados no trabalho, no lar e em atividades de lazer. Fazem parte dessa expansão laptops, notebooks, netbooks, ultrabooks, tablets etc., permitindo "interatividade, [...] mobilidade e [...] portabilidade" e possibilitando "pessoas [concretizarem] tarefas e se [deslocarem] livremente pelo espaço e a qualquer tempo" (CARVALHO, 2017, p. 17). A bola da vez são os telefones móveis, celulares ou Smartphones empregados em um universo de coisas e que, às vezes, usamos para conversar. Eles estão causando transformações diversas nas sociedades, em seus modos de se organizarem e nas relações que as sustentam. Comercializados com alguma timidez até o final do século XX, no século XXI fazem-se cada vez mais presentes por serem fáceis de levar, leves e confluírem diversas mídias (rádios, TVs, jornais, revistas), aplicativos variados (Internet Banking, GPS, agendas e calendários, Facebook, WhatsApp...), tela sensível ao toque, artifícios de multimídia, conectividade à Internet e serviços de e-mail. São constituídos por sistemas operacionais que permitem a sincronização com computadores, tablets e outras máquinas que usam o mesmo sistema. Essa expansão atinge a economia e a política, perpassando a mentalidade das comunidades, das populações e dos docentes - que em tempos de pandemia, são mais assujeitados aos mecanismos digitais -, fazendo parte de novas maneiras de se forjarem sujeitos e de subjetivá-los (SEGATA, 2020). Nesse contexto, entendemos assujeitamento como os modos de tornar o indivíduo sujeito a - no caso, sujeito aos procedimentos e práticas produzidas para o uso e o consumo das tecnologias digitais -, buscando não ofertar mecanismos de questionar ou de produzir resistência às próprias tecnologias digitais.

$\mathrm{Na}$ interseção dessas duas maneiras de conduta da conduta (o controle da formação e do trabalho docente e as tecnologias móveis como modos de subjetivação dos indivíduos, das comunidades e das populações) identificamos a UNESCO e suas proposições. Sob o argumento das transformações provocadas pela expansão das tecnologias móveis e a 
multiplicidade de usos viabilizados por elas, a UNESCO, entre 2012 e 2014, lançou uma série intitulada 'Documentos de trabalho sobre aprendizagem móvel'. Tal série consiste em 14 documentos subdivididos em 6 volumes, tratando das relações entre a promoção das aprendizagens móveis e as políticas públicas e outros 6 volumes que orientam os professores a terem práticas mais proveitosas. São descritas situações e experiências em todos os continentes, além de um volume reunindo temas considerados globais sobre o sucesso de experiências com aprendizagens móveis (UNESCO, 2012). Encerrando a coleção, um volume trata de experiências de compartilhamento da aprendizagem móvel e outro aponta prováveis impactos dessas tecnologias no futuro da educação. No volume 'Aprendizagem móvel para professor' descreve-se a forte demanda por profissionais que os sistemas educacionais de países pobres e em desenvolvimento sofrerão nos próximos anos. Segundo o texto, "o mundo precisa realizar [dois objetivos] muito difíceis simultaneamente [...]: elevar tanto a quantidade quanto a qualidade da força de trabalho global dos professores". Para isso, os documentos propostos evidenciam que "a tecnologia móvel pode ajudar a aproximar os países de ambos os objetivos". Com o intuito de amenizar uma demanda reprimida por milhões de professores, na expectativa do aumento de qualidade da educação, "descrevem algumas das inúmeras formas em que as tecnologias móveis são usadas para apoiar e treinar professores em diferentes regiões e contextos em todo o mundo" (UNESCO, 2012, p. 7, grifos nossos). Dessa série de documentos analisaremos: 'Aprendizagem móvel para professor: temas globais' (2012); 'Iniciando a aprendizagem móvel na América Latina' (UNESCO, 2012a) - ambos em Inglês; 'O Futuro da educação móvel' (UNESCO, 2014) - versão em português. Além desses três documentos, trabalharemos, também, com as 'Diretrizes de políticas da UNESCO para a aprendizagem móvel' (2014a) e 'Tecnologias para transformação da educação' (2014b) - os dois em Português. Escolhemos esses documentos por tratarem da formação e do trabalho docentes por meio de tecnologias digitais de maneira ampla e conceitual, sendo suas noções empregadas nos outros 9 documentos da série 'Documentos de trabalho sobre aprendizagem móvel'. A perpassar esses documentos, define-se a aprendizagem móvel como aquela a envolver o uso de tecnologias móveis, permitindo o estudo em qualquer lugar ou a qualquer hora, podendo ser ou não combinada com outras tecnologias digitais, possibilitando "acessar recursos educacionais, conectar-se a outras pessoas ou criar conteúdos, dentro ou fora da sala de aula" (UNESCO, 2014a, p. 8). É entendida, da mesma maneira, como uma ferramenta importante para que as políticas educacionais atinjam seus objetivos, bem como para facilitar a comunicação interna das escolas e dessas com as famílias.

Tendo em vista uma abordagem teórica de inspiração foucaultiana e como objeto de investigação os documentos da UNESCO, a questão orientadora para as nossas análises pode ser assim descrita: como a formação e o trabalho docentes são produzidos nesses documentos? Em consequência, nosso objetivo é investigar como a formação e o trabalho 
docentes são tratados nas proposições sobre aprendizagem móvel da UNESCO. Nessa direção, problematizamos como o professor é pensado e enformado nesses mesmos textos, em um cenário de mentalidade neoliberal de governo encontrada globo afora. Em suma, como vários outros aspectos da vida, o controle da formação e do trabalho docentes vem acompanhado de uma série de processos de conduta da conduta ligados às tecnologias móveis. Somando-se aos mecanismos de controle constituídos com base em uma mentalidade de mercado e da grande importância que as tecnologias digitais passaram a ter na vida humana, passamos, também, a conviver com a pandemia de Covid-19 e seus impactos sobre o cotidiano social. Por esse motivo nos remetemos à série de documentos produzida no contexto da pandemia pela UNESCO, mesmo que de modo mais periférico.

Sobre a escolha do material analisado, realizamos leituras seletivas de documentos, apoiados na análise de documentos, tratando-se de uma forma de reorganizar os textos com a finalidade de ressaltar alguns elementos para que possa ser extraído o máximo de informação da melhor maneira possível (BARDIN, 2011). Neste artigo, identificamos os documentos analisados segundo um critério temático, buscando trechos que expressem as propostas de funcionamento das políticas públicas para as tecnologias móveis, como elas tratam o trabalho e a formação de professores para atuar com as tecnologias digitais, antes e especialmente durante a pandemia.

Para cumprir o objetivo de análise em relação ao material capturado, na seção seguinte será brevemente apresentada a noção de governamentalidade de Michel Foucault. Logo depois, de maneira sucinta, discutimos a produção de Stephen Ball relacionada a essa mesma noção no contexto das produções de políticas educacionais. A seguir, analisaremos os documentos da UNESCO no que tange à formação e ao trabalho docentes para, na próxima seção, tratarmos das empresas que financiaram a produção desses textos. $O$ artigo será concluído com uma problematização das proposições em questão, apontando as tecnologias móveis como parte de mecanismos de controle da conduta em um cenário de governamentalidade neoliberal. 


\section{BASE TEÓRICO-ANALÍTICA}

O neoliberalismo não pode ser considerado uma criação apenas de nosso tempo. É uma mentalidade que se inspira e, ao mesmo tempo, transforma o liberalismo do final do século XVIII, liberalismo esse que já buscava uma extraordinária centralidade disciplinar de saberes, localizando-os em campos ou em áreas hierarquicamente dispostas, com desdobramentos políticos, científicos e econômicos em muitas facetas da vida pessoal e social (FOUCAULT, 2008a). Neste texto, nos interessa mais especificamente o neoliberalismo que tomou força no pós-Segunda Guerra Mundial. Essa mentalidade estabeleceu como foco de julgamento econômico as políticas governamentais e o modo de agir dos sujeitos. Inventou, propôs e produziu para isso o homem da economia, do mercado, do mérito - o homo oeconomicus.

A partir da década de 1970, o neoliberalismo é a mentalidade que vem orientando a elaboração de muitas políticas públicas concernentes a mecanismos de governo de Estado pautados em lógicas muito similares pelo globo. Na verdade, é possível dizer que essas lógicas alinham-se em torno dos mesmos pressupostos sociais e econômicos. O homo oeconomicus contemporâneo converteu-se no sujeito racional, ciente e competente aos movimentos do mercado, respondendo a eles de "forma não aleatória [e] sistemática", colaborando para a economia definir-se "[...] como a ciência da sistematicidade das respostas às variáveis do ambiente" (FOUCAULT, 2008, p. 368), pautada em valores da utilidade e da eficiência. Assim, para além de uma teoria política, o neoliberalismo tornou-se "toda uma maneira de ser e pensar", sendo suas análises econômicas de mercado utilizadas para decifrar fenômenos não econômicos. Podemos, então, considerá-lo também como "um método de pensamento", criando e se apoiando em uma mentalidade a dar base a "uma grade de análise econômica e sociológica" (FOUCAULT, 2008, p. 301). Nesse neoliberalismo contemporâneo criaram-se um ambiente e uma mentalidade - perpassando todas as relações sociais, passando por organizações sociais e chegando ao Estado e se apoiando na utilidade do homo oeconomicus - com a generalização absoluta da forma do mercado, incorporando-se "um ambiente competitivo no qual reinam as leis da economia" (SHAMIR, 2008, p. 1) no que tange à educação, à saúde, à segurança, à natalidade, à mortalidade, ao casamento etc.

Nesse cenário, Ball (2001) busca elaborar análises educacionais apoiando-se na noção de governamentalidade neoliberal. Ele descreve certas relações de poder-saber que vêm configurando a elaboração e implementação de políticas públicas para a educação. Sob um certo ponto de vista, evidencia como toda uma engenharia de ideias é colocada em prática. Sob outro ponto de vista, evidencia, igualmente, como a recomendação de uma agenda, entendida como um conjunto de medidas, toma nova proporção quando proposta por instituições como Banco Mundial, ONU, UNESCO, exercendo influência nas políticas públicas

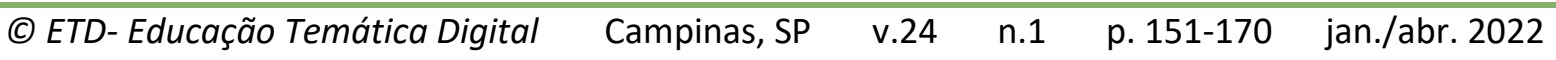


(MAINARDES, 2006). Assim, os regimes de verdade construídos pela governamentalidade neoliberal desejam produzir, sobre a sociedade, um sentimento de inexorabilidade em relação aos caminhos que os Estados devem percorrer para garantir o desenvolvimento econômico, social e também educacional. De acordo com os teóricos neoliberais, a crise das instituições educacionais é, fundamentalmente, "uma crise de qualidade decorrente da improdutividade que caracteriza as práticas pedagógicas e a gestão administrativa da grande maioria dos estabelecimentos escolares" (GENTILLI, 1994, p. 4). Não se trata, portanto, de uma crise de democratização, mas de uma crise gerencial que só pode ser adequadamente resolvida com uma "profunda reforma administrativa do sistema escolar orientada pela necessidade de introduzir mecanismos que regulem a eficiência, a produtividade, a eficácia" (GENTILLI, 1994, p. 5) dos sistemas escolares. A governamentalidade neoliberal transforma a própria educação em mercadoria, um produto altamente lucrativo, que movimenta o mercado de livros didáticos, materiais pedagógicos, cursos de especialização. Dessa maneira, o processo educativo, suas finalidades e justificativas vêm sendo povoados pela lógica mercadológica e é cada vez mais usual a contratação de instituições privadas e/ou nãogovernamentais para trabalhos de intervenção pedagógica nas redes públicas de educação, especialmente municipais (HYPÓLITO, 2010).

Nos materiais citados acima, nessas estratégias e nesses textos temos uma estrutura que favorece determinadas práticas em relação a outras, sob várias formas: orientações, recomendações, diretrizes, relatórios, regras e leis, convocando os sujeitos a interpretarem e criarem respostas com base nelas. Em síntese, os sujeitos devem ser convencidos e se convencerem a conduzir suas condutas (pelo Estado, pelos outros e por si mesmos) pelos parâmetros neoliberais colocados economicamente como naturais e irrefutáveis (BALL, 2014). Com um discurso denunciador, cada vez mais documentos - como os da UNESCO que analisamos - propõem soluções para a educação, deixando de lado o aprofundamento de algumas discussões conceituais e encontrando expressões generalistas ou construções que conseguem se amparar em um novo consenso em torno de uma suposta sociedade do conhecimento e consumo. Constantemente, esses discursos buscam evidenciar a superação do período de políticas antagônicas que marcaram o século XX, para um, que se poderia chamar de 'fim da política', no qual prevalece a postura pragmática, não importando a posição do partido que conduzirá a política. Ela simplesmente estaria dada, cabendo aos Estados e aos sujeitos assimilá-la (BALL, 2014). Um período no qual os critérios técnicos e teóricos a imperarem na constituição das políticas de Estado são empregados para favorecerem o mercado e a contemporânea versão do homo oeconomicus - o sujeito de interesse e empreendedor de si, o perverso sujeito meritocrático (FOUCAULT, 2008). A educação está entre as áreas nas quais essa produção de critérios meritocráticos vem criando impactos que, a partir da década de 1980, bombardeiam os sujeitos que nela atuam. Então, quando a relacionamos com as tecnologias, especialmente as móveis, encontramos uma

\begin{tabular}{|c|c|}
\hline D- Educação Temática Digital & $151-170$ \\
\hline
\end{tabular}


mentalidade para a construção das políticas públicas muito apoiada em mecanismos de controle e governo, aspectos que passamos a abordar a partir de agora nas proposições da UNESCO para a formação e o trabalho docentes e suas consequentes orientações para determinados fins.

\section{A FORMAÇÃO E O TRABALHO DOCENTES}

O documento 'Diretrizes de políticas da UNESCO para aprendizagem móvel' é uma síntese sobre o tema, tendo como público-alvo os gestores e as autoridades envolvidas com a educação. Apresenta-se a opinião de vários experts, visando "auxiliar os formuladores [e reformadores] de políticas a entender[em] melhor o que é aprendizagem móvel e como seus benefícios, tão particulares, podem ser usados como alavanca para fazer avançar o progresso em direção à Educação para Todos" (UNESCO, 2014a, p. 07). Não é difícil constatar que tal auxílio alcançam vários países: "não por acaso, as reformas educacionais promovidas em países como Brasil, Espanha, Inglaterra, Estados Unidos e Argentina apresentam tanta similitude [...], e os mesmos especialistas dali estão a ditar caminhos acolá" (LIMA; MENDES, 2016, p. 717). O mesmo documento traz a definição de aprendizagem móvel como aquela que envolve o uso de tecnologias móveis, permitindo o estudo, em qualquer lugar ou a qualquer hora, podendo ser ou não combinada com outras tecnologias digitais. Essas tecnologias possibilitam "acessar recursos educacionais, conectar-se a outras pessoas ou criar conteúdos, dentro ou fora da sala de aula" (UNESCO, 2014a, p. 8). Assim, evidencia-se a potência da aprendizagem móvel, tendo-se em conta a condição de precariedade e insuficiência do sistema educacional que poderá ser, em parte, superada com os benefícios oferecidos pelas tecnologias móveis.

Ainda sob o princípio da superação das precariedades e insuficiências, são apresentadas dez diretrizes indicadas como ações para que os responsáveis pelas políticas educacionais conduzam as mesmas a fim de atingir a potencialidade apresentada. Entre as propostas contidas nessas diretrizes, encontram-se orientações quanto ao incentivo à formação dos professores, à oferta de infraestrutura adequada, incluindo hardware e software, além do desejo na melhoria da gestão (UNESCO, 2014a). Em diversos momentos, funciona como uma cartilha de orientação, na qual o emprego compromissado por parte dos professores e gestores levará à obtenção dos resultados desejados. Ao argumentarem a favor de um trabalho docente de melhor qualidade, exaltam que "as tecnologias móveis também podem aumentar a eficiência dos educadores, automatizando a distribuição, a coleta, a avaliação e a documentação das avaliações" (UNESCO, 2014a, p. 15, grifos nossos).

Nessa mesma linha, a UNESCO (2014b) lançou um material para orientar as políticas públicas da América Latina para adotarem as aprendizagens móveis como uma das formas para solucionar os problemas educacionais enfrentados. Em suas conclusões, entre as oito

$\begin{array}{llllll}\text { (C) ETD-Educação Temática Digital } & \text { Campinas, SP } & \text { v.24 } & \text { n.1 } & \text { p. 151-170 } & \text { jan./abr. } 2022\end{array}$


estratégias propostas, são ressaltados aspectos de responsabilidade pela aquisição dos aparelhos pelo Estado ou pela família para serem usados pelo alunado. Articuladamente, deve-se estruturar "em primeiro lugar", procedimentos que facilitem "o uso dos dispositivos móveis que [os estudantes] já têm, e, em segundo lugar", colocar "em prática políticas compensatórias" para o ensino e a aprendizagem. Ressaltam que "essas recomendações devem ter como base o princípio da disponibilidade constante da assessoria, suporte e apoio adequados pelo professor sobre como orquestrar os recursos didáticos que estão à disposição" (UNESCO, 2014b, p. 49-50, grifos nossos). Em ambos os documentos da UNESCO (2014a; 2014b), encontramos uma evidente articulação entre eficiência, avaliação e controle da formação e do trabalho docentes, fazendo parte de um conjunto de "discursos que desempenham [...] o objetivo de criar uma noção de que as [transformações] são uma necessidade natural", constituindo-se "em parte inevitável da globalização e do mercado" e exigindo-se "mudanças radicais na forma de organizar, conceber e desenvolver a educação" via formação e trabalho docentes (HYPÓLITO, 2010, p. 1340).

Em dois documentos, a UNESCO (2012; 2014a) apresenta: a possibilidade de expansão do acesso à educação promovida pelas tecnologias móveis, atingindo a formação e o trabalho dos professores e dos sujeitos à margem do sistema formal de ensino; a possibilidade de se ter o telefone celular como apoio a instruções em sala, comunicação administrativa e formação profissional; o papel central dos professores nos projetos de introdução no letramento digital, incluindo a aprendizagem móvel nos sistemas de ensino; a questão da segurança, tanto na necessidade de orientar os alunos a utilizarem com cautela os recursos disponíveis quanto na promoção de campanhas de saúde, acompanhamento e prevenção de doenças. Argumenta-se, igualmente, que "para capitalizar as vantagens das tecnologias móveis, os professores devem receber formação sobre como incorporá-las com sucesso na prática pedagógica", sendo tal investimento governamental na formação, em muitos casos "mais importante que o investimento na própria tecnologia". Por meio de pesquisas da própria UNESCO, mostram que "sem orientação e capacitação, os professores frequentemente utilizam a tecnologia para 'fazer coisas velhas de formas novas', ao invés de transformar e melhorar abordagens de ensino e aprendizagem" (UNESCO, 2014a, p. 30, grifos nossos). Fica evidente a necessidade de transformação do sujeito docente em seu trabalho cotidiano, via formação continuada. Quem contestaria tamanha e tão necessária transformação? Em cenários onde as velhas práticas não trariam novos resultados, a formação e o trabalho docentes são colocados, por meio de orientação e capacitação, como aspectos centrais para o bom uso das potencialidades das tecnologias móveis. A conduta da conduta docente se configura, nesse sentido, como uma lógica, um método de pensamento, uma forma de se portar no cenário contemporâneo global (FOUCAULT, 2008). 
Coerente com a mesma lógica, as séries de documentos da UNESCO (2012; 2012a; 2014; 2014a; 2014b; 2020a; 2021) ainda recomendam: tornar prioritário o desenvolvimento profissional dos educadores; promover a formação de professores para utilização dos modernos aparelhos; estimular a incorporação da aprendizagem móvel nos currículos e no agenciamento de maneiras de compartilhar experiências. Ressaltam o baixo número de materiais produzidos para os dispositivos móveis voltados para os professores, além da necessidade de disponibilizar um número maior de materiais didáticos para esses aparelhos, com facilitado acesso. Por fim, indicam a possibilidade das aprendizagens móveis na formação dos professores de maneira complementar à educação presencial, na modalidade de EAD, incluindo o ensino híbrido como umas das principais prioridades. Assim, com a EAD não se retiraria o docente de seu ambiente escolar, podendo atender um maior número de sujeitos, com custos muito mais baixos, tendo como pano de fundo a autonomia e gerência de si mesmo por parte dos professores em relação ao seu tempo e investimento na melhoria da sua atividade profissional.

Com base em nossa perspectiva, identificamos assim a proposição de uma espécie de filtro neoliberal, uma estratégia de avaliação de custos a implicar nas intervenções do poder público na educação. Sob o foco dessa proposição, não se leva em conta a ambiguidade colocada: por um lado, a argumentação pela melhoria da qualidade; por outro, uma formação em EAD que está longe de cumprir o que vem sendo prometido, a não ser em relação ao seu baixo custo (PEREIRA, 2017). Apresenta-se aí, a nosso ver, "o cinismo de uma crítica [neoliberal] oposta à ação do poder público" a produzir efeitos com sua mentalidade e seus regimes de verdade sobre a formação e o trabalho docentes (FOUCAULT, 2008, p. 338). Daí a importância do homo oeconomicus como sujeito privilegiado da análise econômica neoliberal, como o sujeito a responder "de forma sistemática às modificações nas variáveis do meio" (idem, p. 368). O professor teria, supostamente, apenas uma saída: assumir sua condição de homo oeconomicus, um sujeito de interesse e empreendedor de si, tendo as políticas de Estado a apoiá-lo, promovendo uma auto conduta resiliente para a melhoria da educação escolar. 
Em outro documento, a UNESCO (2014b) volta a realizar estudos sobre os impactos das tecnologias na educação da América Latina, dessa vez com foco na aprendizagem dos alunos das escolas da região, não deixando de ressaltar a formação dos professores dentro do regime de verdade neoliberal. Demonstra-se que na região, a porcentagem de professores que faz uso de tecnologias em casa é significativamente maior do que aquela que faz uso delas em contextos escolares. Há também uma pesquisa que aponta que dois dos três maiores desconfortos dos docentes em relação ao desenvolvimento profissional são "competência tecnológica para o ensino" e "novas tecnologias no trabalho". Ao tratar do caminho para superação de tais dilemas é apontada ou, pelo menos esboçada uma metodologia que partiria do mais familiar para o professor "com soluções tecnológicas que resolvam problemas imediatos, o que irá conferir oportunidades de descobrir o que poderia vir depois", propondo "uma aproximação em círculos concêntricos, ampliando pouco a pouco os limites do conforto, exigindo um pouco mais de cada vez" (UNESCO, 2014b, p. 60). O documento aponta igualmente que os cursos de formação de professores são reconhecidamente os que menos utilizam a Internet. Tal realidade pode ser verificada não só na América Latina como, da mesma forma, nos países desenvolvidos. Com relação à formação continuada, novamente recomenda-se que seja realizada na própria escola, em serviço, empregando ferramentas de EAD, partindo do entendimento que "tanto os professores que já exercem a profissão quanto aqueles que estão entrando no mercado agora precisam de formação e treinamento para aprender a projetar intervenções inovadoras de aprendizagem móvel" (UNESCO, 2014b, p. 51, grifo nosso).

Os formuladores de políticas não devem perder de vista quais as limitações dos professores, como também quais as estratégias para superá-las. A UNESCO - e outros organismos, muitas vezes de forma articulada - propõe formas de políticas para a América Latina, sendo amplamente conhecido o seu papel de formação e influência na produção de sentidos entre agentes públicos na elaboração de políticas para educação (LIMA; MENDES, 2016). Além disso, é importante lembrar que a divulgação das proposições de formação e influência precisam de financiamento. A própria UNESCO (2012) assume sua proximidade com parceiros que financiam seus materiais relacionados às aprendizagens móveis junto aos professores e formuladores de política. Dentro da mentalidade neoliberal, uma pergunta parece-nos óbvia: seria possível ter um financiamento sem ele estar amarrado às estratégias de mercado montadas pelas empresas financiadoras? 


\section{QUEM FINANCIA ESSES DOCUMENTOS?}

A UNESCO é uma organização criada pela Organização das Nações Unidas (ONU). Ambas surgiram como organismos internacionais (dentre outros) logo após a Segunda Guerra Mundial, tratando de questões relacionadas à regulação populacional, à qualidade de vida e aos direitos sociais, em um contexto de Welfare State (Estado de Bem-Estar Social). Levando em conta um cenário complexo (ascensão do neoliberalismo, aumento populacional acelerado, crises econômicas e de credibilidade do Estado, desmonte do Welfare State), "os meios e os recursos [e também as carências] se ampliaram" e foram abordados por diversos organismos internacionais além da ONU e UNESCO (MAUÉS; BASTOS, 2016, p. 699). A Organização para a Cooperação e Desenvolvimento Econômico (OCDE), por exemplo, no final dos anos 1950, passa a sofrer influências do olhar econômico-empresarial sobre o mundo social com a Teoria do Capital Humano, desenvolvida nos anos 1950 por membros da Escola de Chicago, interpretando que "as competências, habilidades e as aptidões de um indivíduo qualquer constituem, [...] pelo menos virtualmente e relativamente independente da classe social a que ele pertence, seu capital", reconhecendo-se a si e aos outros "como uma microempresa" (COSTA, 2009, p. 177). Nessa mesma linha, nos anos 1960, a OCDE investiu na Teoria do Capital Humano como uma perspectiva de melhoria dos sistemas educacionais de países em desenvolvimento (PAPADOPOULOS, 1994), além do Banco Mundial propor políticas públicas para educação com o objetivo de combate à pobreza sob o mesmo referencial, a partir dos anos 1970 (BANCO MUNDIAL, 2000). Porém será nos anos 1980 que aumentou e se evidenciou "a participação/ingerência [de cunho evidentemente neoliberal] desses organismos nos países em desenvolvimento em diferentes áreas" (MAUÉS; BASTOS, 2016, p. 699).

Entre os organismos internacionais, a UNESCO tem como foco de ação a educação e a cultura. Especificamente para atuar na educação, recebe financiamento de variadas origens: além de verbas da ONU, de ajuda humanitária, de doações de países à própria UNESCO, dinheiro de fundos internacionais e de empresas privadas. Percebemos que uma série de documentos sobre o uso de dispositivos móveis em contextos educacionais elaborados pela UNESCO contou com maior ou menor participação da iniciativa privada do setor de telecomunicações e de instituições educacionais ligadas a grupos econômicos: Nokia (UNESCO, 2012; 2012a; 2014; 2014a) Fundação Santillana, especializada na área educacional; Samsung, do setor de eletrônicos; a Microsoft; Fundação Telefônica; além do Insper, instituição de Ensino Superior do ramo de negócios (UNESCO, 2014b). Em UNESCO (2020a), são citados como financiadores governos, organizações internacionais e fundações privadas. Já em UNESCO (2021), encontramos 24 organizações multilaterais, 38 empresas privadas (a maioria do setor de tecnologias digitais), 102 organizações da sociedade civil e sem fins lucrativos (boa parte ligada às discussões sobre educação e inovação por meio das tecnologias 
digitais) e 9 'parceiros da mídia'. Dois aspectos apresentam-se como centrais: 1) comumente, empresas (públicas ou privadas) não costumam financiar proposições contrárias a seus interesses; 2) quanto maior o financiamento privado, maior será a repercussão de seus interesses no produto resultante do financiamento. Por dedução, processos de unificação e homogeneização financiados por grandes corporações (mesmo que propostos por organismos internacionais) correm o risco de repercutirem as estratégias dessas mesmas corporações e seus reflexos possivelmente atingirão várias instâncias sociais, culturais e políticas (BALL, 2014).

É cada vez mais evidente que as políticas relacionadas à educação e às tecnologias móveis propostas pela UNESCO estejam ligadas a interesses privados. Entre as empresas mais frequentes no grupo de financiadoras e colaboradoras tem-se a finlandesa Nokia (UNESCO, 2012; 2012a; 2014; 2014a). Especificamente, em alguns documentos, a empresa é citada como uma parceira (UNESCO, 2012) e como grande responsável pelas contribuições financeiras (UNESCO, 2014). Talvez seja muito difícil pensar em educação e tudo que a ela se relaciona sem mecanismos de controle. A questão central, então, estaria em quais contextos sociais, políticos e econômicos tais mecanismos têm sido propostos e a quem tem servido. É observável que "a política educacional está sendo feita em novas localidades, em diferentes parâmetros, por novos atores e organizações". Com foco nas proposições sobre as políticas públicas para o emprego de tecnologias móveis na educação, "redes políticas são um tipo de 'social' novo, envolvendo tipos específicos de relações sociais, de fluxos e de movimentos", constituindo "comunidades de políticas, geralmente baseadas em concepções compartilhadas de problemas sociais e suas soluções" (BALL, 2014, p. 57).

Um exemplo desse modelo de solução é o Nokia MoMath, um aplicativo bem simples (software de trocas de mensagens curtas entre professores e alunos), integrado a jogos digitais de Matemática nos quais os alunos podem registrar seus escores e compará-los com os outros. Segundo o documento da UNESCO (2014, p. 49, grifos nossos), o sucesso desse aplicativo "pode ser atribuído sobretudo às ricas e diversificadas parcerias que se estabeleceram entre organizações de uma ampla variedade de setores, incluindo governos locais e nacionais, ONGs e empresas de telecomunicação". Segundo o mesmo documento, o aplicativo foi elaborado com base em três princípios: 1) o professor estar disponível e disposto a dar reforço escolar fora de suas horas de sala de aula; 2) os exercícios matemáticos devem ter relações com atividades gameficadas e de fácil acesso pela Internet. Um terceiro objetivo é expresso pela Nokia: promover a venda de mais celulares e seus aplicativos, em articulação com o pacote de serviços do Nokia Life, em países onde a população de jovens consumidores tenha grande possibilidade de aumentar. Com isso, de maneira supreendentemente transparente, a Nokia alinha seus interesses comerciais às necessidades 
educacionais identificadas em algumas partes do mundo 4 . Infelizmente, as soluções aos problemas educacionais são propostas em outras instâncias que não o espaço público e coletivo de discussão, mas tornadas públicas e coletivas por determinadas estratégias e procedimentos. Dessa forma, existe uma tendência muito grande das empresas de países desenvolvidos influenciarem os mecanismos de controle sobre a educação propostos nos documentos, especialmente porque muitos desses mecanismos estão relacionados a produtos tecnológicos que elas oferecem. Assim, produtos, modelos e exemplos localizáveis tornam-se generalizáveis e supostamente viáveis de serem empregados em outros lugares fora de seus contextos de produção. Em consequência, é possível deduzir que materiais produzidos - muitas vezes sem se levar em conta os complexos processos de ensino e aprendizagem envolvidos com a educação - são apontados como soluções para o sucesso escolar. Está presente aí uma mentalidade neoliberal de mercado a divulgar e padronizar artefatos produzidos em determinados contextos como úteis a qualquer contexto (BALL, 2014).

O uso de dispositivos móveis parece mais um dos esforços realizados para suprir a carência de profissionais da educação presente em muitos países, entre eles o Brasil, sem necessariamente atentar-se para duas coisas: 1 ) esses dispositivos foram produzidos por empresas privadas para serem vendidos no mercado em geral, às vezes sem preocupação alguma com os processos de ensino e aprendizagem escolar; 2) as reais causas da falta de atratividade e permanência dos profissionais na área de educação. Organismos internacionais como o Banco Mundial, a OCDE e a UNESCO - é verdade, de maneiras diferentes, - participam do fortalecimento de um vasto mercado a ser ocupado pelas empresas educacionais e tecnológicas, posicionando o assunto da formação de professores no centro das discussões, embora nem sempre com o correspondente aporte financeiro por parte desses organismos, dessas empresas ou pelos Estados (MAUÉS; BASTOS, 2016). Há uma confluência de princípios e soluções na direção de se fortalecer o mercado, sendo que organismos internacionais, "ONGs e interesses e influências de empresas podem constituir, separadamente ou em conjunto, uma poderosa alternativa de política para o 'fracasso' do Estado". Formam-se assim "novas redes e comunidades de políticas" configuradas e apoiadas em "determinados discursos e conhecimentos" (BALL, 2014, p. 74).

Talvez o uso de aplicativos citados pela UNESCO e seus patrocinadores possa ser útil em determinados contextos. Como já vimos ao longo deste artigo, vários aspectos deveriam ser levados em conta para se promover seu uso em diferentes contextos. Acrescentamos aqui mais um: a importância dada ao investimento para a valorização docente. Organismos

\footnotetext{
4 Para saber mais sobre as estratégias de mercado e venda da Nokia ligadas à educação acesse https://www.theguardian.com/sustainable-business/nokia-mobile-social-investment-business-africa.
} 
internacionais, corporações transnacionais e, a reboque, os Estados dão pouca ou nenhuma atenção ao investimento para a valorização docente. Estudos comparativos entre países desenvolvidos e em desenvolvimento demonstram que as situações de atração e acolhimento de profissionais em setores estratégicos, com possibilidade de mobilidade para formação, são completamente distintas. Além disso, a carreira docente é repleta de instabilidade e insegurança financeira (PEREIRA, 2017). Nos documentos aqui analisados, vemos quase nenhuma atenção dada ao investimento na valorização docente, a não ser como forma de uma simples denúncia.

\section{CONCLUSÃO}

Um universo de possibilidades vem se abrindo na relação entre educação e tecnologia, beneficiando ambas as áreas (quanto maior o nível de escolarização, melhor será a qualidade dos ambientes e produtos e vice-versa, criando-se um lopping). Igualmente, acreditamos ser um caminho sem volta, no qual indivíduos estão cada vez mais conectados às tecnologias e suas formas, constituindo-se como sujeitos de certa espécie, espécie essa que herdará o mundo. Igualmente não negamos que a UNESCO tenha uma preocupação com a discussão social relacionada à pobreza extrema e às mais diversas discriminações e exclusões sobre as quais a educação pode agir e colaborar para a sua superação, entendendo "os sujeitos sociais [que] aparecem [nos documentos da UNESCO] como dotados de potencialidade para entender e mudar a realidade na qual estão inseridos" (REZENDE, 2019, p. 124). O interesse com a produção de sujeitos, por meio da educação escolar, preocupados em transformar sua realidade está centralmente presente nos documentos elaborados no contexto da pandemia (UNESCO, 2020; 2020a; 2021). Neles, não temos dúvidas, são problematizadas como "as injustiças sociais potencializam as injustiças escolares" (REZENDE, 2019, p. 133) e precisam ser combatidas. Esse também não é o problema dos documentos da UNESCO. Parece-nos ser um problema político relacionado à não crítica, ou mesmo, uma aderência sem reflexão a um modelo de mercado.

No âmbito internacional é emblemática a ação da UNESCO com suas séries de documentos aqui analisadas. Esses, formulados a partir de realidades diversas, aparecem como modelos para conduzir os variados programas educacionais para um maior nível de excelência. Eles orientam e modificam não só as práticas pedagógicas, como também as atividades escolares e o próprio fazer político dos países (BALL, 2001; 2014). A estratégia de tornar a educação um setor de serviços negociáveis - princípio aprovada pela OMC em 1994 (RIBEIRO, 2006) -, utilizando as tecnologias como um procedimento inovador, vem tomando força e ganhando espaço como algo afeito ao controle e ao governo dos Estados. Tal estratégia vem sendo incentivada nas propostas dos organismos internacionais (MAUÉS; BASTOS, 2016). Pesquisas ressaltam similaridades nas ações políticas e orientações sobre 
formação de professores no Brasil e nas propostas dos organismos internacionais. Alguns textos mostram que os documentos brasileiros sobre aprendizagem móvel, bem como a respeito da capacitação dos profissionais envolvidos, assumem um discurso no intuito de atender aos pleitos apresentados pelos organismos internacionais sobre o uso dessas tecnologias em contextos educacionais (CARVALHO, 2017; EVANGELISTA, 2017).

Entre as questões centrais postas pelo mercado - repercutidas e apoiadas pelos organismos internacionais, mesmo com uma configuração discursiva preocupada com aspectos da ascese do sujeito - está a necessidade de compreender o papel do Estado diante dos dilemas políticos, econômicos, culturais e sociais. Nesse sentido, surgiria uma suposta cidadania universal pautada na lógica das "economias de mercado livre" (BALL, 2001, p. 108) que resolveria os dilemas acima colocados. Essa lógica afirma que o mercado, "e por sua vez a competição entre as pessoas, é natural à condição humana", sendo o mercado apenas a "expressão [dessa] necessidade básica". No neoliberalismo do século XX, tal condição do sujeito teve um nome: homo oeconomicus. No século XXI, de um lado, sua suposta existência natural continua a justificar a economia de mercado livre. De outro, ele é a invenção (perversa) dos ideólogos do mercado livre sob a forma de sujeito de interesse e empreendedor de si (LIMA; MENDES, 2016; BALL, 2014). Desde o momento que a UNESCO trata das tecnologias móveis no início dos anos 2010, conforma-se com essas duas lógicas, tanto antes como durante a pandemia.

O emprego das tecnologias móveis na educação proposto pela UNESCO, na busca de controlar-se melhor a formação e o trabalho docentes, está completamente imbricado com uma mentalidade neoliberal de mercado. Como procuramos mostrar ao longo do artigo, especialmente nos trechos descritos com 'grifos nossos', aparecem nos documentos da UNESCO termos como força de trabalho, aumentar a eficiência, disponibilidade constante, orientação e capacitação, tendo como ação importante treinar os professores. Eles, com certeza, não fazem parte de uma lógica didático-pedagógica de pesquisadores, estudiosos e ativistas que pensam e propõem uma educação progressista e transformadora. Por outro ângulo, promovem práticas consagradas em estratégias de coaching e training produzidas por uma mentalidade neoliberal, com sopros de ar - bem leves - que carregam alguma inovação.

Nos cenários estudados, a aprendizagem e a tecnologia móvel continuam a servir a mecanismos de controle que não emergiram agora, não sendo simplesmente inventados em mundos digitais, pela globalização ou em cenários pandêmicos. Seus procedimentos, suas estratégias, suas formas de governo têm profundas raízes históricas no Ocidente (FOUCAULT, 2008; 2008a) e talvez estejam aí as grandes dificuldades em combatê-los. Nosso intuito analítico e político é compreender e expor como funcionam algumas proposições da UNESCO em relação ao uso das tecnologias móveis, participando do controle da formação e do

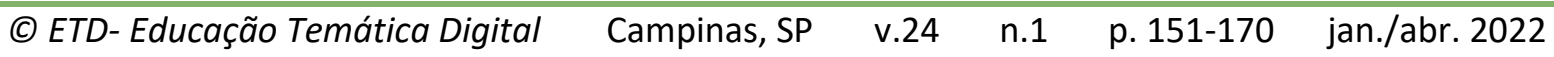


trabalho docentes. Ao fazermos isso, imaginamos que suas fissuras, suas aberturas e suas ambiguidades possam aparecer. E a luta por mecanismos menos cínicos e mais coletivos, tendo o sujeito como foco - e não simplesmente o mercado -, tenha mais argumentos e força.

\section{REFERÊNCIAS}

BALL, S. J. Diretrizes políticas globais e relações políticas locais em Educação. Currículo sem Fronteiras, v. 1, n. 2, p. 99-116, jul./dez. 2001. Disponível em:

https://www.curriculosemfronteiras.org/vol1iss2articles/ball.pdf. Acesso em: 21 nov. 2020.

Educação Global S. A.: novas redes de políticas e o imaginário neoliberal. Ponta Grossa: UEPG, 2014.

BANCO MUNDIAL. Estrategia sectorial de educación. Washington, D.C.: Grupo del Banco Mundial, 2000. Disponível em:

https://documents1.worldbank.org/curated/en/469761468150873366/pdf/196310SPANISH OBOX0338884B.pdf. Acesso em: 06 ago. 2021.

BARDIN, L. Análise de conteúdo. São Paulo: Edições 70, 2011.

CARVALHO, C. R. As tecnologias móveis na escola e o trabalho docente. 2017. Tese

(Doutorado) - Universidade Estadual Paulista, Faculdade de Ciências e Tecnologia, 2017.

CASTIONI, R.; MELO, A. A. S.; NASCIMENTO, P. M. Universidades federais na pandemia da Covid-19. Ensaio, v. 29, n. 111, abr./jun. 2021. DOI: https://doi.org/10.1590/s010440362021002903108.

COSTA, S. S G. Governamentalidade neoliberal, Teoria do Capital Humano e Empreendedorismo. Educação e Realidade, v. 34, n. 2, p. 171-186, maio/ago. 2009. Disponível em: https://seer.ufrgs.br/educacaoerealidade/article/view/8299/5537. Acesso em: 06 ago. 2021.

EVANGELISTA, R. M. F. As políticas de tecnologias móveis na educação: técnicas de governamento dos outros e de si. 2017. Dissertação (Mestrado) - Universidade Federal de Ouro Preto, 2017.

FOUCAULT, M. O sujeito e o poder. In: DREYFUS, H. L.; RABINOW, P. (Org .). Michel Foucault: Uma trajetória filosófica. Rio de Janeiro: Forense Universitária, 1995.

. O nascimento da biopolítica. São Paulo: Martins Fontes, 2008.

. Segurança, território, população. São Paulo: Martins Fontes. 2008a.

GENTILLI, P. Neoliberalismo e Educação: manual do usuário. In: GENTILLI, P.; SILVA, T. T. (Org.). Escola S.A. Brasília: CNTE, 1994. 
HYPÓLITO, A. M. Políticas curriculares, estado e regulação. Educação e Sociedade, v. 31, n. 113, p. 1337-1354, out./dez. 2010. DOI: https://doi.org/10.1590/S0101$\underline{73302010000400015}$.

LIMA, G. P. C; MENDES, C. L. Currículo, avaliação e a constituição do sujeito docente. Práxis Educativa, v. 11, n. 3, set./dez. 2016, p. 714-735. DOI: https://doi.org/10.5212/PraxEduc.v.11i3.0011.

MAINARDES, J. Abordagem do ciclo de políticas públicas: uma contribuição para a análise das políticas educacionais. Educação e Sociedade, Campinas, v. 27, n. 94, p. 47-69, jan./abr. 2006. DOI: $\underline{\text { https://doi.org/10.1590/S0101-73302006000100003 }}$

MAUÉS O. C.; BASTOS R. S. As políticas de educação superior na esteira dos organismos internacionais. RBPAE, v. 32, n. 3, set./dez. 2016, p. 699-717. DOI: https://doi.org/10.21573/vol32.

PAPADOPOULOS, G. Education 1960-1990: the OECD perspective. Paris: OECD, 1994. Disponível em: http://hdl.voced.edu.au/10707/44807. Acesso em: 06 ago. 2021.

PEREIRA, D. O. A formação docente no contexto da universidade aberta do Brasil. Dissertação (Mestrado) - Universidade Federal de Ouro Preto, 2017.

REZENDE, M. J. Justiça escolar e justiça diferencialista nos documentos adotados por órgãos das nações unidas (pnud e unesco). Lua Nova, n. 108, 121-135, 2019. DOI: http://dx.doi.org/10.1590/0102-121135/108.

RIBEIRO, G. F. Afinal, o que a organização mundial do comércio tem a ver com a educação superior? Revista Brasileira de Política Internacional, n. 49, v. 2, 2006, p. 137-156.

Disponível em: https://www.scielo.br/pdf/rbpi/v49n2/a08v49n2.pdf. Acesso em: 13 nov. 2020.

SEGATA, J. A colonização digital do isolamento. Cadernos de Campo, v. 29, n. 1, p. 163-171, 2020. DOI: https://doi.org/10.11606/issn.2316-9133.v29i1p163-171.

SHAMIR, R. The age of responsibilization: on market-embedded morality. Economy and Society, v. 37, n. 1, p. 1-19, fev. 2008. DOI: 10.1080/03085140701760833.

UNESCO. Mobile Learning for teacher: global themes. Paris: UNESCO, 2012. Disponível em: http://unesdoc.unesco.org/images/0021/002164/216452E.pdf. Acesso em: 16 nov. 2020.

UNESCO. Turning on mobile learning in latin america. Paris: UNESCO, 2012a. Disponível em: http://unesdoc.unesco.org/images/0021/002160/216080E.pdf. Acesso em: 14 nov. 2020.

UNESCO. O futuro da aprendizagem móvel. Brasília: UNESCO, 2014.

UNESCO. Diretrizes de políticas para aprendizagem móvel. Brasília: UNESCO, 2014a.

(C) ETD-Educação Temática Digital Campinas, SP $\quad$ v.24 $\quad$ n.1 $\quad$ p. 151-170 jan./abr. 2022


UNESCO. Tecnologias para a transformação da educação. Brasília: UNESCO, 2014b.

UNESCO. Five steps to support education for all in the time of COVID-19. Paris: UNESCO, 2020. Disponível em: http://www.iiep.unesco.org/en/maintain-operational-capacitiesduring-school-closures. Acesso em: 16 nov. 2020.

UNESCO. Informe de seguimiento de la educación en el mundo 2020: inclusión y educación: todos e todas sin excepción. Paris: UNESCO, 2020a.

UNESCO. Supporting learning recoveryone year into COVID-19: The Global Education Coalition in action. Paris: UNESCO, 2021. Disponível em: https://unesdoc.unesco.org/ark:/48223/pf0000376061. Acesso em: 20 maio 2021.

UNESCO; UNICEF; BM; WFP. Marco de ação e recomendações para a reabertura de escolas. Abr. 2020. Disponível em: https://www.unicef.org/brazil/media/8761/file/marco-de-acao-erecomendacoes-para-a-reabertura-de-escolas.pdf. Acesso em: 15 nov. 2020.

Revisão gramatical realizada por Angela Ignez Marcellini Massa

E-mail: angelaignezmassa@hotmail.com 